\title{
ACADEMIC STAFF PERCEPTIONS OF \\ ADMINISTRATIVE QUALITY AT UNIVERSITIES
}

A refereed full-paper presented at the Australian Association for Research in Education

Conference held in Fremantle form December 3 to 6 December 2001

\author{
Russell F. Waugh \\ Edith Cowan University
}

Key words: higher education, university, service quality, administrative quality, academic staff, administrative staff, measurement techniques

Running head: ADMINISTRATION QUALITY

18 July 2001

Total no. of words 8000

Address correspondence to Dr Russell F. Waugh at

Edith Cowan University, Pearson Street, Churchlands,

Western Australia, 6018 


\section{ABSTRACT}

This is a theoretical paper that gives direction as to how Administrative Quality at a university can be measured on an interval scale. The measure is based on a model of academic staff perceptions in relation to Central, Faculty or School administration (as the case may be). The Australian government has set up a new Australian University Quality Agency in 2001 and one of its objectives is to measure quality in administration (management). Academic staff perceptions ofAdministrative Quality are proposed to consist of two 1st order aspects, operationally defined by a number of 2 nd order aspects. These are: Reliability and Responsiveness (Administrative Contact, Provision of Administrative Material, Confident and Dependable Administrative Advice and Advanced Notice of Administrative Changes), and Assurance and Empathy (Courteousness and Confidence in Contact, Individual and Understanding Contact and Feeling Secure Contact). The 21 stem-items measuring each 2nd order aspect are set up in Guttman patterns, conceptually ordered by increasing 'difficulty'. Academics are asked to respond to each of the 21 stem-items in two parts, conceptually ordered from 'easy' to 'hard': Ideally, this is what I think my university administration should do('easy'), and This is what my university administration actually does ('hard'). This model has been pilot tested successfully with a small sample $(\mathrm{N}=27)$ and is now ready for a full test.

\section{ACADEMIC STAFF PERCEPTIONS OF}

\section{ADMINISTRATIVE QUALITY AT UNIVERSITIES}

The Australian Minister for Education, Training and Youth Affairs in the Howard Liberal government, The Honourable Dr David A. Kemp MP, has indicated that an Australian University Quality Assurance Agency will be set up in 2001 (Kemp, December, 1999). There will be a distinction between two main functions. First, the accreditation function involving approval for new universities to operate, use words like 'university' and 'degree', and approve and accredit courses of study leading to degrees and university awards will continue to be the responsibility of States and Territories. A second function is the quality assurance process for universities and this will be administered by the Quality Assurance Agency. It is expected that the States and Territories will use common protocols and procedures that will be subject to periodical review by the Quality Assurance Agency. The Minister has indicated that the evaluation of quality will involve a 'whole of institution approach incorporating teaching and learning, research and management, both onshore and offshore' (Kemp, 1999, p6). It is this last aspect, management, and the measure of its quality, that is the subject of the present paper. However, before this is explained, there is a need to explain some background to the formation of the Australian University Quality Assurance Agency.

Since the late 1980s, Australian universities were being signaled that they would be called to account for the quality of education provided. Performance indicator was the then 'in-word'. Universities were asked to provide evidence of various Performance Indicators and government funding would be linked to the achievement of the indicators (Dawkins, 1988). The Honourable John Dawkins MP was the then Australian Minister for Employment, Education and Training in the Hawke Labor government. At the time, this topic was debated with some tension in universities. Tying funding to performance, especially when there are no good measures of performance that take account of various inputs and outputs, was considered to be bad practice and unfair. Professor Hattie, then at the University of Western 
Australia, wrote about the problems with this approach in 1990, and he reflected the views of many academics. Performance indicators tended to be superficial and easily quantifiable such as absolute numbers of students ... percentage of completions ... flows of money ... (Soutar and McNeil, 1996, p.72). Nevertheless, the first audit of quality at universities began in 1993, with two further quality audits in 1994 and 1995.

It was considered by many academics that there were at least four aspects driving the accountability movement in Australian universities. First, there was the general accountability for quality that 'invaded' the state governments in Australia across both the private and public sectors in the1980s. There seemed to be moves 'everywhere' to be more efficient, to 'downsize', to provide good service, and to be accountable. Second, there was the move by the Australian government to make university students pay a portion of their university fees. This had an 'in turn' effect by making students query the service being provided by academics that, in some cases, was found wanting by students. It was reported, for example, that the Australian government had received many complaints about poor teaching and a drop in academic standards at universities (Harman, 1994, p.29). Third, overseas students were paying full-fees at universities in Australia. These students were questioning the service provided and, in some cases, it was found wanting (Steadman and Dagwell, 1990). Four, Australian universities were in competition with universities from other countries for overseas students, and with each other, and this created another 'in turn' effect for accountability. They had to show that they were providing education as good as or better than other countries, and that their education was 'value for money'. In the United Kingdom, a Charter of Education required tertiary institutions to consider 'students as customers' and for academics to respond to student needs and requests (Department of Education, 1993). Many students seemed to like this general approach - it was a big change from the 'old' view when some academics were much more concerned about their research than about their students - and it had an 'in turn' effect on attitudes to quality by academics in other countries like Australia that were in competition for overseas students.

Viewing university students as customers created some tensions in universities (see Sharrock, 2000). Many academics did not believe that students were 'just customers' or that universities were 'to just give students what they wanted', including jobs (Sharrock, 2000). This was making universities too much aligned with businesses. It was then a view, not too far removed, for academics to be viewed as customers of university administration. Pitman (2000) examined the extent to which university staff perceived students and academics as customers in Australia. It was found that administrative staff has ambivalent feelings towards treating academics as customers and he highlighted interpersonal skills between the two groups as a major challenge facilitating customer service. On the other hand, administrative staff was more accepting of students as customers and staff incorporated a mentor role into the processes of dealing with students. Administrative staff related more closely to students as customers than to academics as customers. Robson (2000) investigated the relationship between general and non-general staff in higher education in Australia, United Kingdom, the Netherlands and Finland. It was found that general staff 'know their place', realise that their role is 'not the main game in higher education', and they do much to support and enhance student experiences. They know that they have to support academic staff in their main roles of research and teaching at institutions of higher education.

This leads to the problem for this paper. There is a need to be able to measure on a proper interval scale academic staff perceptions of administrative service; that is, to be able to make a measure of Administrative Quality in universities that is comparable across all universities. This view has support from Cliff (1994) in regard to higher education in New Zealand when he could find no good measures of service quality applicable to higher education. The best measure he found was from the business area (explained later). There is a need to have a theoretical model of administrative quality in higher education in the 
current climate, to test the model in various universities, and modify the model based on evidence. This paper proposes a model based on previous research and a method of testing the model using Rasch measurement to create a scale of Administrative Quality. There are three benefits from this. First, it would provide university administrators with knowledge about the quality of administration in their universities. Second, it would give government a research basis for monitoring quality of administration. Third, it will give tertiary institution researchers a theoretical model that they can test in a variety of universities and have comparability of quality of administration.

\title{
Previous Research on Measuring Service Quality in Business
}

Service has traditionally been a business term and the measurement of service quality had its beginnings in the business literature. Business has at least four conceptions of service quality (see Parasuraman, Zeithaml and Berry, 1988). One is perceived quality versus objective quality. Customers have a perception of quality that is different from marketers. Customers are more subjective than marketers. Marketers view service quality more conceptually than customers and customers are more likely to vary in their perception of quality than marketers. Two is perceiving quality as an attitude, an overall evaluation of a product or service. Customers think in terms of the characteristics of the service and its provider, and use criteria to evaluate quality. Attitude is perceived as an overall judgement relating to the 'goodness' of the service. Three is perceived satisfaction and usually relates to each specific service provided. Continued favourable incidents of satisfaction lead to customers developing a perception of high service quality. Four is expectations compared to perceptions. Customers perceive service quality by comparing their expectations with their perceptions of performance. Expectations are perceived as 'wants' or 'desires' by customers and lead to what services they think should be provided. This conception of service has been used to develop a scale of service quality in business (SERVQUAL). A search of the literature found that this was the best researched measure of service quality to date and that it could be adapted for use in higher education.

SERVQUAL (Parasuraman, Zeithaml and Berry, 1985) is a questionnaire designed to measure service quality that has been developed, refined and tested in the business area in recent years, 1985-1994 (see a series of publications Parasuraman, Zeithaml and Berry, 1994, 1993, 1991, 1988, 1986, 1985; Parasuraman, Berry and Zeithaml, 1991, 1990). SERVQUAL consists of five dimensions: Reliability, Assurance, Tangibles, Empathy and Responsiveness (see Figure 1) and is composed of 22 items answered by customers in a seven point Likert response set. The questionnaire is administered twice: once to gain customers' expectations and second to gain their perception of performance.

\author{
Place Figure 1 about here
}

\section{Problems with SERVQUAL applied 'as is' at universities}

Seven general aspects of the SERVQUAL scale, if applied directly to measuring Administrative Quality in universities, are called into question. First, the scale contains one main aspect that is not applicable to universities. Tangibles, meaning the appearance of physical facilities, equipment, personnel and communication materials, would not be applicable to customer service in universities and hence can be deleted. Two, SERVQUAL is not designed to measure the Administrative Service provided to customers on one occasion and, at the same time, measure the Administrative Service provided to 
other customers on numerous occasions, and measure the Administrative Service for all on the same scale. Three, Likert (1932) response formats contain a discontinuity between the response categories of disagree and agree. That is, the response measurement format is not ordered from low to high and those who are undecided, don't want to answer, are unclear or just neutral, will answer the middle (neutral) category. This means there is a consequent interpretation problem for SERVQUAL using seven point responses (strongly agree to strongly disagree, with middle categories untitled). Four, SERVQUAL doesn't test the linkage of expectations and actual service by calibrating all measures of service and all item 'difficulties' on the same scale. Five, the items measuring Administrative Service are not separated into their sub-groups on the questionnaire, so that it is not clear to the customers what is being measured. Six, positively and negatively worded items are often mixed to avoid the fixed response syndrome (a common procedure in traditional measurement). There is some evidence that this causes an interaction effect between items in modern measurement models (see Andrich \& van Schoubroeck, 1989). Consequently, it is considered better to word all items in a positive sense when using modern measurement models. Seven, the analysis of SERVQUAL has only been performed with traditional measurement programs and ordinal level scales. Modern measurement programs are now available to create interval level measures in which item 'difficulties' and customer measures of Administrative Quality can be calibrated on the same scale (see Andrich, 1988a, 1988b; Andrich, Sheridan, Lyne, and Luo, 2000; Rasch, 1960/1980; Wright, 1985). They also test the conceptual structure of Administrative Service, including their dimensional nature. Rasch measurement model analysis has been shown as appropriate to use in measuring variables like attitudes and quality (see Andrich, 1985, 1982; Waugh, 2001a,b, 1999,1998a,b; Wright and Masters, 1982, 1981).

\section{Changes made to SERVQUAL}

The following changes to SERVQUAL were made to overcome the seven problems referred to above and to make the new scale applicable to measuringAdministrative Quality at universities. The new stem-items for the scale were based on a model of two 1st order aspects defined by a number of 2 nd order aspects. Twenty-one stem-items based on the four aspects of Administrative Quality in SERVQUAL (tangibles was deleted) were devised to apply to academics at university. These stem-items were combined into two 1 st order aspects in order to provide a more logical and consistent structure, applicable to universities (see Figure 2). Each stem-item was answered in two response sets: Ideally, this is what I expect my university administration to do, and This is what my university administration actually does. The items were ordered under their respective sub-group names that make it clear to academics what aspects are being measured. They were written in a positive sense, so as to be applicable to the new response format. The response format was changed in two ways. First, two columns were added for responses, one for Ideally, this is what I expect my university administration to do, and This is what my university administration actually does. Second, the response categories were changed to an ordered format to provide an ordered measurement structure: rarely or on no occasions, on some occasions, on most occasions, and on all or nearly all occasions. This measurement structure allows for an academic who is only a customer a few times, as well as for academics who are customers on many occasions. There are now 21 items relating to Ideally, this is what I expect my university administration to do and, in direct correspondence, 21 items relating to This is what my university administration actually does. A sample is given in Figure 3 and the full scale is given in the Appendix. Data relating to the questionnaire could be collected and analyzed with a recently developed Rasch measurement model computer program (Andrich, Sheridan, Lyne and Luo, 2000) in order to create a scale of Administrative Quality and test its conceptual structural. 


\section{Criteria for measurement}

Seven measurement criteria have been set out by Wright and Masters (1981) for creating an interval level scale that measures a variable (see also Wright, 1985). They are, first, an evaluation of whether each item functions as intended. Second, an estimation of the relative 'difficulty' of each valid item along the scale that is the same for all persons is required. Third, an evaluation of whether each person's responses form a valid response pattern is checked. Four, an estimation of each person's relative score (attitude or achievement) on the scale is created. Five, the person scores and the item scores must fit together on a common scale defined by the items and they must share a constant interval from one end of the scale to the other so that their numerical values mark off the scale in a linear way. Six, the numerical values should be accompanied by standard errors which indicate the precision of the measurements on the scale; and seven, the items should remain similar in their function and meaning from person to person and group to group so that they are seen as stable and useful measures. These criteria are used in the computer program Rasch Unidimensional Measurement Models (RUMM) (Andrich, Sheridan, Lyne and Luo, 2000).

\section{Measurement Model}

The application of a Rasch measurement model to create a scale has advantages over the use of Classical measurement. A Rasch procedure produces scale-free measures and sample-free item 'difficulties' (Andrich, 1988b; Rasch, 1980/60; Wright and Masters, 1982). The mathematics of a Rasch model produces differences between pairs of measures and pairs of item 'difficulties' that are sample independent. Rasch methods produce interval level scales. That is, equal differences between numbers on the scale represent equal amounts of the measures, just as the differences between 1 and $2 \mathrm{~cm}$. and between 5 and $6 \mathrm{~cm}$. represent equal amounts of length.

In Classical measurement, where the measures are the sums of scores on the items and the item 'difficulties' are not calibrated on the same scale as the measures, the measures are strictly sample dependent. Classical measurement cannot produce anything better than a ranking scale that will vary from sample to sample. The goal of a proper scale for Administrative Quality (a scale akin to a ruler) cannot be accomplished through Classical measurement.

In Rasch measurement, when all the items fit the measurement model, there is a predominant single trait influencing all persons who answer all the items. Recently, DeMars (2001) and Fan (1998) have found that person ability measures using Classical measurement gave comparable results to those using a Rasch Measurement Model. This implies that there is no need for a Rasch analysis, and that summing individual item scores in a variable is good enough. However, this is misleading. Fan (1998, p.368) also says that the results for the one-parameter Rasch model 'should be viewed with extreme caution' (p.368) because $30 \%$ of the items miss-fitted the one-parameter Rasch model. DeMars (2001) found similar results, with similar examples of miss-fitting items, and gives a similar caution when commenting on the one-parameter model. The problem here is that one doesn't know, in advance, which items to use in the scale. A Rasch analysis is needed to determine which items fit the conceptual model and the measurement model. A Rasch analysis is also needed to produce a proper scale in which both measures and item 'difficulties' are calibrated together, which classical measurement does not do. A Rasch analysis also tells the researcher which items to delete because they are not part of the 
predominant trait, thus reducing the contribution of 'noise' to the measure. A counter claim is that content validity is decreased by deleting items that seem to be conceptually valid and that Classical measurement then provides higher content validity by using more of the conceptually valid items.

Rasch measurement requires the discrimination factor to be the same for all the items to form a proper scale and the wording of items is important in gaining that item fit. A small change in the wording can make a difference in whether items fit a Rasch analysis. Many items are often deleted in Rasch analysis so that the discrimination condition can be fulfilled. On the other hand, Classical measurement allows the discrimination of the items to vary considerably. Factor analysis and inter-item correlations determine which items 'hang together' to produce a scale in Classical measurement.

The zero point on the scale does not represent zero Administrative Quality. It is an artificial point representing the mean of the item difficulties, calibrated to be zero, in Rasch measurement. It is possible to calibrate a true zero point, if it can be shown that an item represents zero Administrative Quality. There is no true zero point in the proposed scale. In Classical measurement there is no true zero point either, but the difficulties of the items are not calibrated against the measures and are often not conceptualised and calibrated to form a scale of items from 'easy' to 'hard'. In Rasch analysis, items are conceptualised and created initially in a scale from 'easy' to 'hard', and the data analysis tests this conceptualisation.

The RUMM computer program (Andrich, Sheridan, Lyne and Luo, 2000) parameterises an ordered threshold structure, corresponding with the ordered response categories of the items. The thresholds are boundaries located between the response categories and are related to the change in probability of responses occurring in the two categories separated by the threshold. When the thresholds are ordered in line with the ordered response categories, the data fit the Rasch measurement model better. No check is normally made that persons answer the response categories consistently and logically in Classical measurement.

The RUMM program substitutes the parameter estimates back into the model and examines the difference between the expected values predicted from the model and the observed values using two tests of fit: one is the item-trait interaction and the second is the itemperson interaction.

The item-trait test-of-fit (a chi-square) examines the consistency of the item parameters across the person measures for each item and data are combined across all items to give an overall test-of-fit (see Andrich and van Schoubroeck, 1989, pp479-480 for the equations). This shows the collective agreement for all item 'difficulties' across persons of differing Administrative Quality measures along the scale. No such check is normally done on this aspect in Classical measurement.

The item-person test-of-fit examines both the response patterns for persons across items and for items across persons. It examines the residual between the expected estimate and the actual values for each person-item summed over all items for each person and summed over all persons for each item (see Styles and Andrich, 1993, p.914 or Andrich and van Schoubroeck, 1989, p.482 for the equations). The fit statistics approximate a distribution with an expected mean near zero and a standard deviation near one, when the data fit the measurement model. Negative values indicate a response pattern that fits the model too closely (probably because response dependencies are present, see Andrich, 1985) and positive values indicate a poor fit to the model (probably because other measures ('noise') are present). Again, no checks are done on this aspect in Classical measurement. 
In Rasch measurement, one can use a model to fit the data (traditional approach) or model the data to fit strict measurement criteria (Rasch approach). The traditional approach has been to produce a complex measurement model to fit the data using, for example, two person parameters (ability and guessing) and two item parameters ('difficulty' and discrimination) to form a model that would predict the data. The Rasch approach uses strict measurement criteria (described elsewhere in this paper) so that only items which fit the criteria can be ordered from 'easy' to 'hard' to form an interval level scale. These are the valid items measuring the variable. While there are disagreements about the two approaches (see Andrich, 1989; Divgi, 1986; Goldstein, 1980, 1979: Traub, 1983), the Rasch approach offers three advantages. First, it only uses items that fit the measurement criteria to form a valid measure of the variable. A check is made to see that persons respond to the valid items in a logical and consistent manner to form a scale and so 'noise' is considerably reduced. (In traditional measurement, groups of items as factors are identified, but no check is made that the item responses are answered in a logical and consistent pattern to form a scale). Second, the Rasch method creates an interval scale where items are ordered from 'easy' to 'hard' on the same scale as the Administrative Quality measures. This is not done in traditional measurement which only creates ordinal or ranking level measures. Third, it enables the items relating to Ideally, this is what I expect my university administration to do, and This is what my university administration actually does to be calibrated on the same scale simultaneously. Traditional techniques use correlations between the two aspects, without any simultaneous calculations. This typically produces low positive correlations in conflict with theory.

\section{Model and Measurement of Academic Staff Perceptions of Administrative Quality}

It is expected that the formation of academic staff perceptions of Administrative Quality at a university is likely to be a complex process. While it may be difficult to understand the process of its formation for every academic, it ought to be possible to build a model, based on some main aspects, that provides considerable help to university administrators charged with administering a quality service. It ought also to be possible to make some periodic measures of academic staff perceptions of Administrative Quality to discover any changes in administrative service, as perceived by staff, reasonably quickly. We should be able to improve considerably our current methods of monitoring and detecting changes in administrative service quality.

The model was based on four simple ideas that when integrated would help explain academic staff perceptions of Administrative Quality as a complex variable. The first involved the creation of a structure based on two main aspects Reliability and Responsiveness, and Assurance and Empathy, with each operationally defined by a number of sub-aspects. Reliability and Responsiveness was defined by the sub-aspects Administrative contact, Provision of administrative material, Confident and dependable administrative advice, and Advanced notice of administrative changes. Assurance and Empathy was defined by the sub-aspects Courteousness and confidence, Individual and understanding contact, and Caring and secure contact. The second involved creating stemitems in an ordered pattern by 'difficulty' within each sub-aspect. The structure of academic staff perceptions of Administrative Quality was then based on sub-sets of stem-items in patterns of ordered 'difficulty', each aligned from 'easy' to 'hard'. The third involved an ordered response set of categories for each of the stem-items. These areldeally, what I think university administration should do, (expected to be 'easy' on average) and What my university administration actually does (expected to be 'harder' on average). What I think university administration should actually do, ideally was expected to be stated by the academics in terms of how often this happens (rarely or none, some, most, or every 
occasion). It was expected that this would reflect the academics' needs and expectations, all internally and covertly contained within the their minds, but now generally expressed in terms of what they expect to happen at university. What my university administration actually does was expected to be stated in terms of their experiences with administrative staff. The fourth involved calibrating all the 'difficulties' of the items (from 'easy' to 'hard') onto the same scale as the measures of Administrative Quality (from low to high), using a Rasch Measurement Model.

\section{A New Scale of Academic Staff Perceptions of Administrative Contact}

The following material provides an example of the conceptual and model thinking involved with the construction of the scale for one of the sub-groups, Individual and Understanding Contact, under Assurance and Empathy.

\section{Expected Ordering by 'Difficulty' Pattern for the Items}

It was expected that most academics would find it 'easy' to say that they think that ideally, administration can be expected to Provide individual attention to their administrative queries (item 31). It is expected that there would be some variation in academic responses around this. It is expected that most academics would find it 'harder' to say that they think administration Provides individual attention, in a caring and understanding way, to their administrative queries (item 33) and that there would be some variation around this. This is because item 33 involves 'a little bit more individual understanding and contact' conceptually than item 31. It is expected that most academics would find it 'harder still' to say that they think that administration Provides individual and prompt attention from understanding staff who are always available during office hours for administrative queries (item 35) and that there would be some variation around this. This is because item 35 involves 'a little bit more individual and understanding contact' conceptually than item 33. So it was expected that these three stem-items would form an ordered pattern of responses by 'difficulty', on average, from 'easy' to 'hard', when academics reported that this is Ideally, what I expect university administration to do. This is the vertical ordering of stem-items by 'difficulty' in the questionnaire set out in Figure 3 (see also the Appendix).

Similarly, it was expected that this vertically ordered pattern of 'difficulties' for the academics' views of Ideally, what I expect university administration to do in relation to the three stemitems (as explained above) would be repeated for their views of This is what my university actually does (items 32, 34, 36). These patterns can be seen in Figure 3 . That is, for academic views of This is what my university administration actually does, the items would be ordered in 'difficulty' from 32 ('easiest') through 34 ('harder') to 36 ('hardest').

There is also a horizontal ordering of items by 'difficulty'. For example using items 31 and 32 , academics are expected to find it 'easy' to say that Ideally, my university administration should provide individual attention to my administrative queries on every occasion and 'harder' to say that My university administration actually does provide individual attention to my administrative queries on every occasion. This horizontal ordering by 'difficulty' is expected to occur for items 33 and 34, and also for items 35 and 36, in the same sub-group.

A similar pattern of ordering by 'difficulty' in both the vertical and horizontal directions are expected for items in the other sub-groups, by similar reasoning. 


\section{Pilot Testing}

The questionnaire has been pilot tested with academics $(\mathrm{N}=27)$ at an Australian university. The results supported the model. Items were ordered by 'difficulty' from 'easy' to 'hard' vertically within each sub-group, as conceptualised in the model. Similarly, items were ordered from 'easy' to 'hard' horizontally within each sub-group, as conceptualised in the model. The questionnaire is now ready for testing across universities.

\section{How the Questionnaire can help Administrators Monitor Administrative Quality}

The Administrative Quality questionnaire can help university administrators monitor the provision of service quality. First, it can be used as a partial checklist to remind the service providers to take account of all the aspects affecting Administrative Quality, as they go about their daily administrative work. Second, theAdministrative Quality questionnaire can be administered to groups of academics on a repeated measure basis, as required, so that Administrative Quality can be monitored. The scale produced is at the interval level and can be used nation-wide to compare administrative service, if that is required. The focus can be on Central, Faculty or School administration, as the case may be.

The Rasch measurement model computer program (Andrich, Sheridan, Lyne, and Luo, 2000) will calculate the 'difficulties' of each of the items that fit the model and, on the same scale, it will calibrate the Administrative Quality measure for each academic in line with the university's service provided.

By examining the item 'difficulties' for each of the three aspects response aspects (Ideally, this is what I expect my university administration to do, and This is what my university administration actually does), it will be possible to see if these are ordered from 'easy' to 'hard' as predicted by the model. By examining the mean item 'difficulties' for each of the sub-groups, it will be possible to see which sub-groups are 'easy' and which are 'hard'. The 'easy' items and the 'easy' sub-groups are those with which most academics have a positive view. These are the ones for which administrators have provided good service, in the view of the academics, although it does depend on the wording of the items. The 'hard' items and sub-groups are those with which academics find it most 'difficult' to have a positive view of the service provided (although again, it depends on the wording of the item). So while the item 'difficulties' for each of the responses Ideally, this is what I expect my university administration to do, and This is what my university administration actually does will vary from stem-item to stem-item, for any particular item their' difficulties' will be ordered from 'easy' to 'hard'.

\section{Conclusions}

The issue of Administrative Quality provided by universities in Australia is to be examined by a new Australian University Quality Assurance Agency set up by the Australian government from 2001. The issue of how Administrative Quality is to be measured is still to be determined by that Agency. A search of the literature for measures of Administrative Quality has revealed none suitable for universities. A model of Administrative Quality was created from a recent model of service quality, used in the business area, and an instrument used to measure of service quality, SERVQUAL. The model has been revised and adapted for use in universities.

The new model is based on two main aspects, Reliability and Responsiveness, and Assurance and Empathy. Reliability and Responsiveness is operationally defined by 
Administrative contact, Provision of administrative material, Confident and dependable administrative advice, and Advanced notice of administrative changes. Assurance and Empathy is operational defined by Courteousness and confidence in contact, Individual and understanding contact, and Caring and secure contact. A questionnaire of Administrative Quality, based on the model was devised. The items of the questionnaire were conceptualised in Guttman patterns of 'difficulty' within each sub-group. This paper should be of help to tertiary education administrators and tertiary institution researchers who wish to measureAdministrative Quality on a proper interval-level scale using the recently developed computer program RUMM (Andrich, Sheridan, Lyne and Luo, 2000). Another advantage here is that the research would be testing a theoretical model of Administrative Quality and that there is the potential to advance our theoretical understanding of the measurement of service quality at tertiary institutions.

\section{References}

Andrich,D.(1989), "Distinctions between assumptions and requirements in measurement in

the Social sciences", in Keats, J.A., Taft, R., Heath, R.A. and Lovibond, S. (Eds.), Mathematical and Theoretical Systems, pp. 7-16, Elsevier Science Publishers, Amsterdam (North Holland).

Andrich, D. (1988a), "A General Form of Rasch's Extended Logistic Model for Partial Credit Scoring", Applied Measurement in Education, Vol. 1 No. 4, pp. 363-378.

Andrich, D. (1988b), "Rasch Models for Measurement", Sage university paper on quantitative applications in the social sciences, series number 07/068, Sage Publications, Newbury Park, CA.

Andrich,D.(1985), "A latent trait model for items with response dependencies: Implications for test construction and analysis", in Embretson, S. E. (Ed.), Test design: developments in psychology and psychometrics (pp. 245-275), Academic Press, Orlando.

Andrich,D.(1982), "Using latent trait measurement to analyse attitudinal data: a synthesis of viewpoints", in Spearitt, D. (Ed.), The improvement of measurement in education and psychology, (pp. 89-126), ACER, Melbourne.

Andrich, D., Sheridan, B., Lyne, A., and Luo, G. (2000), "RUMM: A Windows-based Item Analysis Program Employing Rasch Unidimensional Measurement Models", Murdoch University, Perth, WA. 
Andrich, D. and van Schoubroeck, L. (1989), "The General Health Questionnaire: A psychometric analysis using latent trait theory", Psychological Medicine, Vol.19, pp.469-485.

Buttle, F. (1996), "SERVQUAL: review, critique, research agenda", European Journal of Marketing, Vol. 30 No. 1, pp.8-32.

Cliff, A. (1994), "Measuring quality in New Zealand polytechnics", Journal of Tertiary Education Administration, Vol.16 No.1, pp.45-53.

Dawkins, J.S. (1988), Higher Education: A policy statement, AGPS, Canberra.

DeMars, C. (2001), "Group differences based on IRT scores: Does the model matter?" Educational and Psychological Measurement, Vol.61 No.1, pp.60-70.

Department of Education. (1993), The Charter for Higher Education, HMSO, London. Divigi, D.R. (1986), "Does the Rasch model really work for multiple choice items? Not if you look closely", Journal of Educational Measurement, Vol.23 No.4, pp.283-298.

Fan, X. (1998), "Item response theory and classical test theory: An empirical comparison of their item/person statistics", Educational and Psychological Measurement, Vol.58, pp.357-381.

Goldstein, H. (1980), "Dimensionality, bias, independence and measurement scale problems in latent trait test score models", British Journal of Mathematical and Statistical Psychology, Vol.33, pp.234-246.

Goldstein, H. (1979), "Consequences of using the Rasch model for educational assessment",

British Journal of Educational Research, Vol.5, pp.211-220.

Harman, G. (1994), "Australian higher education administration and the quality assurance movement", Journal of Tertiary Education Administration, Vol.16 No.1, pp.25-43 Hattie, J. (1990), "Performance indicators in education", Australian Journal of Education, Vol. 34 No.3, pp.249-276.

Kemp, D.A. (1999), Quality assured: A new Australian Quality Assurance Framework for university education, speech given by The Hon. Dr D.A. Kemp, Federal Minister for 
Education, Training and Youth Affairs at the seminar on the New Quality Assurance Framework, in Canberra, Australia, 10 December 1999.

(http://www.deet.gov.au/archive/ministers/kemp/dec99/ks101299.htm)

Likert, R. (1932), "A technique for the measurement of attitudes", Archives of Psychology, No. 140.

Parasuraman, A., Berry, L.L. and Zeithaml, V.A. (1991), "Perceived service quality as a customer-based performance measure: An empirical examination of organizational barriers using an extended service quality model", Human Resource Management, Vol.30 No.3, pp.335-364.

Parasuraman, A., Berry, L.L. and Zeithaml, V.A. (1990), "An empirical examination of relationships in an extended service quality model", Marketing Science Institute, Cambridge, MA.

Parasuraman, A., Zeithaml, V.A. and Berry. L.L. (1994), "Reassessment of expectations as a

comparison standard in measuring service quality: implications for future research", Journal of Marketing, Vol.58, January, pp.111-124.

Parasuraman, A., Zeithaml, V.A. and Berry. L.L. (1993), "Research note: more on improving service quality measurement", Journal of Retailing, Vol.69 No.1, pp.140-147.

Parasuraman, A., Zeithaml, V.A. and Berry. L.L. (1991), "Refinement and reassessment of the SERVQUAL scale", Journal of Retailing, Vol.67 No.4, pp.420-450.

Parasuraman, A., Zeithaml, V.A. and Berry. L.L. (1988), "SERVQUAL: A multiple-item scale for measuring consumer perceptions of service quality", Journal of Retailing, Vol.64 No.1, pp.12-37.

Parasuraman, A., Zeithaml, V.A. and Berry. L.L. (1986), "SERVQUAL: A multiple-item scale for measuring customer perceptions of service quality", Journal of Retailing, Spring, pp.12-40.

Parasuraman, A., Zeithaml, V.A. and Berry. L.L. (1985), "A conceptual model of service 
quality and its implications for future research", Journal of Marketing, Vol.49 , Autumn, pp.41-50.

Pitman, T. (2000), "Perceptions of academics and students as customers: A survey of administrative staff in higher education", Journal of Higher Education Policy and Management, Vol.22 No.2, pp.165-175.

Rasch, G. (1980/1960), Probabilistic models for intelligence and attainment tests (expanded edition), University of Chicago Press, Chicago.

Robson, I. (2000), " 'Them and Us' - General and non-general staff in higher education", Journal of Higher Education Policy and Management, Vol.22 No.2, pp.203-210.

Sharrock, G. (2000), "Why students are not (just) customers (and other reflections on Life after George)", Journal of Higher Education Policy and Management, Vol.22, No.2, pp.149164.

Soutar, G. and McNeil, M. (1996), "Measuring service quality in a tertiary institution", Journal of Educational Administration, Vol.34 No.1, pp.72-82.

Steadman, G.T. and Dagwell, R.H. (1990), "A survey of overseas students in Queensland", Australian Universities' Review, Nos.1and 2, pp.59-63.

Styles, I. and Andrich, D. (1993), "Linking the standard and advanced forms of the Raven's Progressive Matrices in both the pencil-and-paper and computer-adaptive testing formats", Educational and Psychological Measurement, Vol.53 No.4, pp.905-925.

Traub, R.E. (1983), "A priori considerations in choosing an item response model", in R.K.Hambelton (Ed.), Applications of item response theory, pp.57-70, Pergamon, New York, NY.

Waugh, R.F. (2001a), "Quality of student experiences at university: A Rasch measurement model analysis", Australian Journal of Education, Vol.45 No.2, pp.181-205

Waugh, R.F. (2001b), "Measuring ideal and real self-concept on the same scale, based on a multi-faceted, hierarchical model of self-concept", Educational and Psychological Measurement, Vol.61, No.1, pp.85-101.

Waugh, R.F. (2000), "Measuring attitudes and behaviours to studying and learning for 
university students: A Rasch measurement model analysis", Paper presented the Australian Association for Research in Education at the University of Sydney, December 4-7, 2000.

Waugh, R.F. (1999), "Approaches to studying for students in higher education: A Rasch measurement model analysis", British Journal of Educational Psychology, Vol.69, No.1, pp.63-79.

Waugh, R. (1998a). "A Rasch measurement model analysis of an approaches to studying inventory for students in higher education". Paper presented at the Latent Trait Theory Conference: Rasch Measurement, held at the University of Western Australia, January 2224, 1998

Waugh, R.F. (1998b), "A revised Course Experience Questionnaire for student evaluation of university courses", Paper presented at the 1998 CEQ Symposium, held at the University of NSW, 28th -30th September 1998,Sydney, Australia, and printed in proceedings, The Course Experience Questionnaire Symposium 1998, Hand, T. and Trembath, K. (Eds.), 99/2, pp.61-76, Evaluations and Investigations Programme (DETYA), Canberra.

Wright, B.D. (1985), "Additivity in psychological measurement", in Roskam, E.E. (Ed.),

Measurement and Personality Assessment, pp.101-112, Elsevier Science

Publishers, Amsterdam.

Wright, B. and Masters, G. (1982), Rating scale analysis: Rasch measurement, MESA Press,

Chicago, IL.

Wright, B. and Masters, G. (1981), The measurement of knowledge and attitude (Research memorandum No. 30), University of Chicago, Department of Education,

Statistical Laboratory, Chicago, IL. 


\section{APPENDIX}

THIS QUESTIONNAIRE IS ANONYMOUS. PLEASE DON'T PUT YOUR NAME OR ANY IDENTIFICATION ON IT.

PLEASE READ THE CONSENT AND COVER PAGE.

QUESTIONNAIRE: QUALITY OF ADMINISTRATION (to be answered by academics)

Please rate the 42 items according to the following response format and place a number corresponding to Ideally, this is what I think my university administration should do, and This is what my university administration actually does provide for academic staff, on the appropriate line opposite each statement:

On all or nearly all occasions put 4

On most occasions put 3

On some occasions put 2

Rarely or on no occasion put 1

Example Items 1-3

If you expect your university administration to provide good administrative advice, ideally, every time, put 4; and if you think your university actually provides good administrative advice some of the time, put 2.

Item 1. Provide good administrative advice. 42

Item no. Item wording Ideally This is

this is what what my

I think my university

university administration

administration actually should do does

Sub-Scale: Reliability and Responsiveness 
Administrative contact with Central (or Faculty) (or School) Management

2. Provide good administrative advice when

I request it (by telephone or email or mail).

3-4 Return my calls promptly (by telephone or email

or mail) with the correct administrative advice.

5-6 Provide prompt administrative services to me with

the appropriate and error-free paper-work at the

promised time, after I request it.

Provision of Administrative Material by Central (or Faculty) (or School) Management

7-8 Provide error-free information relating to my

personal leave, travel and research records when

I request them (by telephone or email or mail).

9-10 Provide error-free policy and other documents

(or tells me accurately where to find them)

when I request them.

11-12 Send copies of error-free policy and other

documents to me (by email or mail) by the

time promised.

\section{Confident and Dependable Administrative Advice from Central (or Faculty) (or School) Management}

13-14 Provide confident verbal advice in handling

my academic administrative problems.

15-16 Provide dependable and right-the-first-time

advice in handling my academic administrative

problems, when I request it. 
17-18 Provide dependable, correct and supportive

administrative advice, when helping me with my

administrative problems.

On all or nearly all occasions put 4

On most occasions put 3

On some occasions put 2

Rarely or on no occasion put 1

Item no. Item wording Ideally This is

this is what what my

I think my university

university administration

administration actually should do does

Advanced Notice of Administrative Changes by Central (or Faculty) (or School) Management

19-20 Provide advanced notice of changes in administrative procedures (by email or mail) affecting me.

21-22 Provide advanced notice and a willingness to discuss 
the changes in administrative procedures with me.

23-24 Provide advanced notice, seek academic input and

is willing to discuss the administrative changes

with me, to help me implement them better.

\section{Sub-Scale: Assurance and Empathy}

Courteous and Confidence in contact with Central (or Faculty) (or School) Management

25-26 Provide courteous attention to my

administrative queries.

27-28 Provide courteous attention from knowledgeable

administrators that instills confidence in

the administration.

29-30 Provide courteous attention with prompt follow-up

services, as appropriate to my administrative

queries.

Individual and Understanding contact with Central (or Faculty) (or School) Management

31-32 Provide individual attention to my

administrative queries.

33-34 Provide individual attention, in a caring and

understanding way, to my administrative queries.

35-36 Provide individual and prompt attention from

understanding staff who are always available

during office hours for administrative queries. 
Feeling Secure: Caring contact with Central (or Faculty) (or School) Management

37-38 Provide advice that makes me feel secure in

my administrative transactions.

39-40 Provide advice that makes me feel secure and confident that my administrative decisions

are correct.

41-42 Provide advice and information that makes me feel that they care about 'doing a good job' and have an empathy with academics.

Are there reasons, beyond the control of the Faculty and School Management, why they cannot provide any services at the standard required? Please explain briefly.

Thank you for your help in answering this questionnaire. It is appreciated. 
Dimensions of SERVQUAL Definition of dimensions Items

Reliability The ability to perform the promised 4

service dependably and accurately

Assurance The knowledge and courtesy of employees and 5

their ability to convey trust and confidence

Tangibles The appearance of physical facilities, equipment 4

personnel and communication materials

Empathy The provision of caring, individualized attention 5

to customers

Responsiveness The willingness to help customers and to 4 provide prompt service

Figure 1. Dimensions of SERVQUAL

Source: Buttle, 1996, p.9

1st Order Aspects 2nd Order Aspects (Operational definition of 1st orders)

Reliability and Responsiveness Administrative Contact (3 stem-items)

Provision of Administrative material (3 stem-items)

Confident and Dependable Administrative advice (3

stem-items)

Advanced Notice of Administrative Changes (3 stem-

items)

Assurance and Empathy Courteous and Confidence in Contact (3 stemitems) 
Individual and Understanding Contact (3 stem-items)

Feeling Secure and Caring Contact (3 stem-items)

Figure 2. Model of Academic Perceptions of Administrative Quality

Note. There are 21 stem-items, each answered in two responses, making 42 items. The two responses are Ideally, this is what I think the university administration should do, and This is what my university administration actually does (see Appendix).

QUESTIONNAIRE: QUALITY OF ADMINISTRATION (to be answered by academics)

Please rate the 42 items according to the following response format and place a number corresponding to Ideally, this is what I think my university administration should do, and This is what my university administration actually does provide for academic staff, on the appropriate line opposite each statement:

On all or nearly all occasions put 4

On most occasions put 3

On some occasions put 2

Rarely or on no occasion put 1

Example Items 1-3

If you expect your university administration to provide good administrative advice, ideally, every time, put 4; and if you think your university actually provides good administrative advice some of the time, put 2.

Item 1. Provide good administrative advice. 42

Item no. Item wording Ideally This is

this is what what my 
I think my university

university administration

administration actually should do does

\section{Sub-Scale: Reliability and Responsiveness}

Administrative contact with Central (or Faculty) (or School) Management

3. Provide good administrative advice when

I request it (by telephone or email or mail).

3-4 Return my calls promptly (by telephone or email

or mail) with the correct administrative advice.

5-6 Provide prompt administrative services to me with

the appropriate and error-free paper-work at the

promised time, after I request it.

Individual and Understanding contact with Central (or Faculty) (or School) Management

31-32 Provide individual attention to my

administrative queries.

33-34 Provide individual attention, in a caring and

understanding way, to my administrative queries.

35-36 Provide individual and prompt attention from

understanding staff who are always available

during office hours for administrative queries.

Figure 3. Sample of items from questionnaire on Administrative Quality 